\title{
Optimal Fault Location Identification in Power Distribution Systems with Inverter-Interfaced Distributed Generations
}

This paper was downloaded from TechRxiv (https://www.techrxiv.org).

\section{LICENSE}

CC BY 4.0

SUBMISSION DATE / POSTED DATE

03-03-2022 / 08-03-2022

\section{CITATION}

Kahnamouei, Ali Shakeri; lotfifard, saeed (2022): Optimal Fault Location Identification in Power Distribution Systems with Inverter-Interfaced Distributed Generations. TechRxiv. Preprint. https://doi.org/10.36227/techrxiv.19294688.v1

$\mathrm{DOI}$ 


\title{
Optimal Fault Location Identification in Power Distribution Systems with Inverter-Interfaced Distributed Generations
}

\author{
Ali Shakeri Kahnamouei, Student Member, IEEE, Saeed Lotfifard, Senior Member, IEEE
}

\begin{abstract}
This paper proposes a fault location identification method for power distribution systems with inverter-interfaced distributed generations (IIDGs). The proposed method is not restricted to any specific types of data and is able to fully utilize all available types of data in power distribution systems for enhancing the accuracy of results. The measurement set may include synchronized voltage and current measurements collected by Micro-phasor measurement units (Micro-PMUs) and/or unsynchronized measurements collected by legacy measuring devices, active and reactive power measurements, pseudo measurements of load values, and virtual measurements based on Kirchhoff's laws. The proposed method explicitly considers uncertainties in the measurement set and is applicable for different load types. Simulations results on IEEE 34-bus feeder demonstrate the accuracy of the proposed method.
\end{abstract}

Keywords-Fault location, distribution systems, inverter-interfaced distributed generators

\section{INTRODUCTION}

$\mathrm{F}$ AULT location identification methods can be in variety of forms such as traveling wave-based methods, voltage sagbased methods, knowledge-based methods, and impedancebased methods. In [1-2] the details of different fault location methods and their strengths and weaknesses are discussed.

This paper is specifically motivated by the following realworld and timely research question: If outside the substation fence data are available from few measuring devices installed along the feeder, which is quite common in modern power distribution systems, how one can fully utilize the collected data to improve the accuracy of the fault location estimation results?

To address the above question, this paper proposes an optimal fault location identification method. To represent the fault, a fictitious node is introduced into the model which its distance from the terminal of the faulted line is considered as an unknown variable. Fault currents are also modeled as unknown current injections into this fictitious node that their values should be estimated. Overall, current injections into each node of the system (i.e. load currents, current injections by distributed generators, and fault currents), voltages of each node of the system and the distance of the fault from the terminal of the faulted line are considered as unknown variables. Once the model is developed, all available data of

A. Shakeri Kahnamouei S. Lotfifard are with the School of Electrical Engineering and Computer Science, Washington State University, Pullman, WA, 99164, USA. (e-mail: s.lotfifard@wsu.edu, $)$. distribution systems are used by the optimal fault location identification method to determine the values of unknown variables. The proposed method identifies the location of the fault while explicitly inaccuracies of pseudo and actual measurements are taken into account.

The rest of this paper is organized as follows: Section II explains the proposed method. Simulation results are provided in section III and conclusions are presented in section IV.

\section{OPTIMAL FAULT LOCATION IDENTIFICATION}

Conventionally current and voltage measurements at the substations are used to identify the fault location in distribution systems. However, some of the simplifications that are made during this process lead to inaccurate results. For instance, laterals are replaced by their equivalent load values. Therefore, the value of voltages at different nodes within the lateral cannot be calculated precisely. In laterals with IIDGs, accurate estimation of voltage values at the point of common coupling (PCC) of IIDGs is necessary for calculating the contributions of IIDGs to the fault. Moreover, systematic approaches should be proposed for utilizing possible extra measurements installed along the feeder for improving the results in the presence of uncertain pseudo measurements of loads. For fault location identification in distribution systems, it is not realistic to assume the accurate load values are available. Unlike transmission lines, distribution systems only have limited real time measurements and pseudo measurements are used for modeling load values which have uncertainties. Moreover, depending on the load types (i.e. ZIP load model) the load value may change during the fault period compared to the pre-fault estimated values of loads (i.e. pre-fault base load values). Measurements also have different accuracies and may be synchronized or unsynchronized.

Voltages of each node of the system and load currents are considered as unknown variables.

At load nodes of the system the followings hold:

Real $\left[\mathrm{V}_{\mathrm{n}} \mathrm{I}_{\mathrm{n}}^{*}\right]=\left[\mathrm{P}_{\mathrm{n} \text {-pseudo measurement }}\right]$

Imag $\left[V_{n} I_{n}^{*}\right]=\left[Q_{n}\right.$-pseudo measurement $]$

$\left[V_{n}\right]$ and $\left[I_{n}\right]$ are $3 \times 1$ vectors representing voltages of node $n$

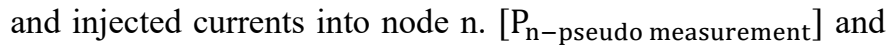
$\left[\mathrm{Q}_{\mathrm{n} \text {-pseudo measurement }}\right]$ are known pseudo measurements of loads at node $\mathrm{n}$ that can be presented in the form of ZIP model or just the base load values if information about the type of the loads is not available. If actual measurements of loads are available, they can be used instead of these pseudo 


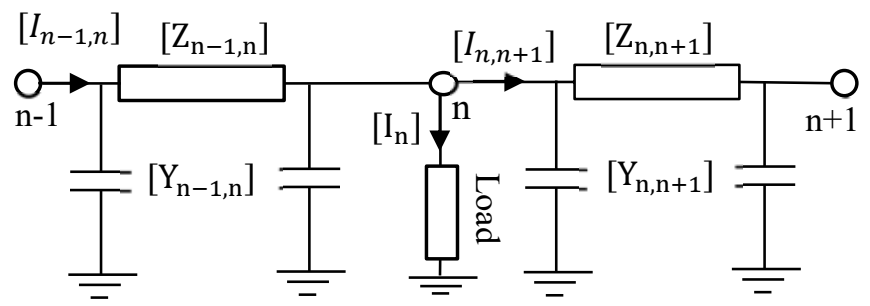

Fig. 1. A portion of a distribution system presented by $\pi$ model

measurements. Equations (1) and (2) can be presented in the cartesian form as follows:

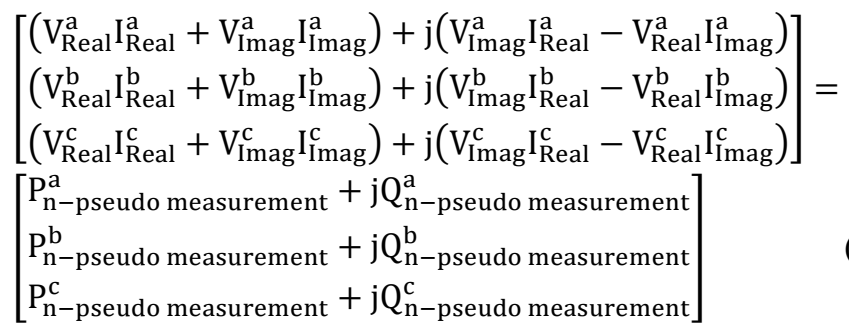

Where $V_{\text {Real }}^{\mathrm{a}}$ and $\mathrm{V}_{\text {Imag }}^{\mathrm{a}}$ represent the real and imaginary parts of the voltage phasor of phase a in cartesian form.

Due to page limitations, the cartesian form of the following equations is not presented. According to Fig. 1, $\left[I_{n-1, n}\right]=\left[I_{n}\right]+\left[Y_{n-1, n}\right]\left[V_{n}\right]+\left[I_{n, n+1}\right]+\left[Y_{n-1, n}\right]\left[V_{n-1}\right]$

where $\left[I_{n-1, n}\right]$ represents the currents of the upstream line to node $\mathrm{n}$ (i.e. the line in the path from node $\mathrm{n}$ to the root node/substation) and $\left[I_{n, n+1}\right]$ represents the currents of the downstream line to node $n$. If more than one line is connected to node $n,\left[I_{n, n+1}\right]$ should be replaced by the sum of all currents of the downstream lines to node $n$. $\left[Y_{n-1, n}\right]\left[V_{n}\right]$ represents the current of capacitors of $\pi$ model of lines connected to node $n$ and is equal to $j \omega\left[C_{n-1, n}\right] / 2$ in which $\left[C_{n-1, n}\right]$ represents the capacitor of the $\pi$ model of line between nodes $n-1$ and $n$.

According to Kirchhoff's Voltage Law (KVL) at node n:

$\left[\mathrm{V}_{\mathrm{n}-1}\right]=\left[\mathrm{V}_{\mathrm{n}}\right]+\left[\mathrm{Z}_{\mathrm{n}-1, \mathrm{n}}\right]\left(\left[\mathrm{I}_{\mathrm{n}-1, \mathrm{n}}\right]-\left[Y_{\mathrm{n}-1, \mathrm{n}}\right]\left[\mathrm{V}_{\mathrm{n}-1}\right]\right)$

$\left[\mathrm{Z}_{\mathrm{n}-1, \mathrm{n}}\right]$ is the series impedance of the line between nodes $\mathrm{n}-1$ and $n$, and $\left[V_{n-1}\right]$ is the voltage of node $n-1$ upstream to node $\mathrm{n}$. If only amplitude measurement of phasor of $\left[\mathrm{I}_{\mathrm{n}-1, \mathrm{n}}\right]$ is available from legacy measuring devices, the following holds:

$\sqrt{\left(\left[I_{n-1, n}\right]_{\text {Real }}\right)^{2}+\left(\left[I_{n-1, n}\right]_{\text {Imag }}\right)^{2}}=\left[I_{n-1, n}\right]_{\text {amplitude-m }}$

Where $\left[I_{n-1, n}\right]_{\text {Real }}$ and $\left[I_{n-1, n}\right]_{\text {Imag }}$ represent the real and imaginary parts of $\left[\mathrm{I}_{\mathrm{n}-1, \mathrm{n}}\right]$ in cartesian form. If synchronized measurement of phasor of $\left[\mathrm{I}_{\mathrm{n}-1, \mathrm{n}}\right]$ is available from MicroPMUs, in addition to (6), the followings are added to the model $\left[\mathrm{I}_{\mathrm{n}-1, \mathrm{n}}\right]_{\text {Real }}=\left[\mathrm{I}_{\mathrm{n}-1, \mathrm{n}}\right]_{\text {Real }-\mathrm{m}},\left[\mathrm{I}_{\mathrm{n}-1, \mathrm{n}}\right]_{\text {Imag }}=\left[\mathrm{I}_{\mathrm{n}-1, \mathrm{n}}\right]_{\text {Imag }-\mathrm{m}}$

Equations similar to (6)-(7) should be considered for voltage measurements.

As shown in Fig. 2, the fault between nodes $\mathrm{k}$ and $\mathrm{k}+1$ is modeled by a fictitious node, $\mathrm{f}$, at which the followings hold:

$\left[\mathrm{I}_{\mathrm{f}, \mathrm{k}+1}\right]=\left[\mathrm{I}_{\mathrm{k}+1}\right]+(1-\mathrm{x})\left[\mathrm{Y}_{\mathrm{k}, \mathrm{k}+1}\right]\left[\mathrm{V}_{\mathrm{k}+1}\right]+\left[\mathrm{I}_{\mathrm{k}+1, \mathrm{k}+2}\right]+(1-$ $\mathrm{x})\left[\mathrm{Y}_{\mathrm{k}, \mathrm{k}+1}\right]\left[\mathrm{V}_{\mathrm{f}}\right]$

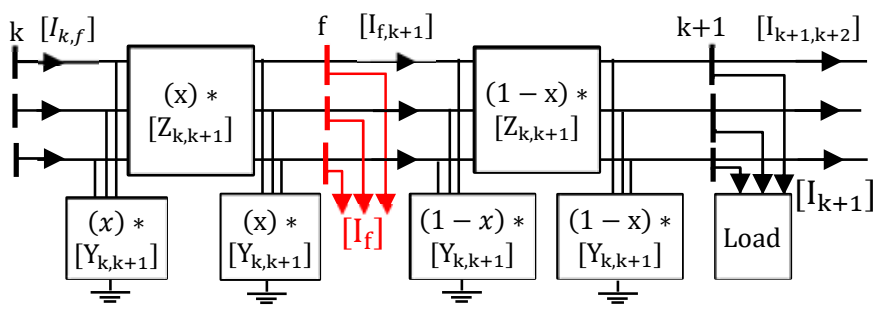

Fig. 2. Schematic of a faulted line between nodes $k$ and $k+1$

$$
\begin{aligned}
& {\left[\mathrm{V}_{\mathrm{f}}\right]=\left[\mathrm{V}_{\mathrm{k}+1}\right]+(1-\mathrm{x})\left[\mathrm{Z}_{\mathrm{k}, \mathrm{k}+1}\right]\left(\left[\mathrm{I}_{\mathrm{f}, \mathrm{k}+1}\right]-\right.} \\
& \left.(1-\mathrm{x})\left[\mathrm{Y}_{\mathrm{k}, \mathrm{k}+1}\right]\left[\mathrm{V}_{\mathrm{f}}\right]\right) \\
& {\left[\mathrm{I}_{\mathrm{k}, \mathrm{f}}\right]=\left[\mathrm{I}_{\mathrm{f}}\right]+(\mathrm{x})\left[\mathrm{Y}_{\mathrm{k}, \mathrm{k}+1}\right]\left[\mathrm{V}_{\mathrm{f}}\right]+\left[\mathrm{I}_{\mathrm{f}, \mathrm{k}+1}\right]+(\mathrm{x})\left[\mathrm{Y}_{\mathrm{k}, \mathrm{k}+1}\right]\left[\mathrm{V}_{\mathrm{k}}\right]} \\
& {\left[\mathrm{V}_{\mathrm{k}}\right]=\left[\mathrm{V}_{\mathrm{f}}\right]+(\mathrm{x})\left[\mathrm{Z}_{\mathrm{k}, \mathrm{k}+1}\right]\left(\left[\mathrm{I}_{\mathrm{k}, \mathrm{f}}\right]-(\mathrm{x})\left[\mathrm{Y}_{\mathrm{k}, \mathrm{k}+1}\right]\left[\mathrm{V}_{\mathrm{k}}\right]\right)}
\end{aligned}
$$

The reactive power consumption by the fault is equal to zero, therefore, the following equation should also be considered:

$$
\left[\begin{array}{l}
\mathrm{V}_{\mathrm{f}, \text { Imag }}^{\mathrm{a}} \mathrm{I}_{\mathrm{f}, \text { Real }}^{\mathrm{a}}-\mathrm{V}_{\mathrm{f}, \text { Real }}^{\mathrm{a}} \mathrm{I}_{\mathrm{f}, \text { Imag }}^{\mathrm{a}} \\
\mathrm{V}_{\mathrm{f}, \text { Imag }}^{\mathrm{b}} \mathrm{I}_{\mathrm{f}, \text { Real }}^{\mathrm{b}}-\mathrm{V}_{\mathrm{f}, \text { Real }}^{\mathrm{b}} \mathrm{I}_{\mathrm{f}, \text { Imag }}^{\mathrm{b}} \\
\mathrm{V}_{\mathrm{f}, \text { Imag }}^{\mathrm{c}} \mathrm{I}_{\mathrm{f}, \text { Real }}^{\mathrm{c}}-\mathrm{V}_{\mathrm{f}, \text { Real }}^{\mathrm{c}} \mathrm{I}_{\mathrm{f}, \text { Imag }}^{\mathrm{c}}
\end{array}\right]=\left[\begin{array}{l}
0 \\
0 \\
0
\end{array}\right]
$$

Depending on the type of faults equations should be added to the model. For example, for a-g faults the following holds

$\mathrm{I}_{\mathrm{f}}^{\mathrm{b}}=\mathrm{I}_{\mathrm{f}}^{\mathrm{c}}=0$

$\mathrm{I}_{\mathrm{f}}^{\mathrm{b}}$ is the fault current of phase b. For b-c faults:

$\mathrm{I}_{\mathrm{f}}^{\mathrm{a}}=0$ and $\mathrm{I}_{\mathrm{f}}^{\mathrm{b}}=-\mathrm{I}_{\mathrm{f}}^{\mathrm{c}}$

The following constraints on $\mathrm{x}$ and $\left|\mathrm{I}_{\mathrm{f}}\right|$ should also be added

$0 \leq x \leq 1$ and $\sqrt{\mathrm{I}_{\mathrm{f}, \text { Real }}^{2}+\mathrm{I}_{\mathrm{f}, \text { Imag }}^{2}} \leq \mathrm{I}_{\mathrm{f} \text {,max }}$

$\mathrm{I}_{\mathrm{f} \text {,max }}$ is a large value of expected maximum short circuit current capacity of the distribution system. Constraints on voltage values of nodes are added as $0 \leq\left|V_{n}\right| \leq V_{\max }$ and similar equations should be added for load and line currents.

In (1)-(15), slack variables are defined for the equations that include actual, pseudo, and virtual measurements. For instance, equation (6) can be represented as follows:

Real $\left(\left[\mathrm{V}_{\mathrm{n}}\right] \times\left[\mathrm{I}_{\mathrm{n}}\right]^{*}\right)+\varepsilon_{\mathrm{n}}-\varepsilon_{\mathrm{n}}^{\prime}=\mathrm{P}_{\mathrm{n} \text {-measured }}$

Where $\varepsilon_{\mathrm{n}} \geq 0$ and $\varepsilon_{\mathrm{n}}^{\prime} \geq 0$ are slack variables.

The objective function is defined as follows:

$\operatorname{Min} \sum_{\mathrm{n}=1}^{\mathrm{M}} \mathrm{w}_{\mathrm{n}}\left(\varepsilon_{n}+\varepsilon_{\mathrm{n}}^{\prime}\right)$

Where $M$ represents the number of measurements in the system (i.e. actual, pseudo and virtual measurements). $w_{n}$ represents the weighting factor for $n^{\text {th }}$ measurement. A larger weighting factor is assigned to more accurate measurements.

To model the contributions of IIDGs to faults, if MicroPMUs are installed at the PCC of IIDGs, the synchronized measured output currents of IIDGs can be directly utilized to represent the contribution of IIDGs. If the measured output active and reactive powers of IIDGs during the fault period are available, IIDGs can be treated as loads with negative power injections. However, if such actual real-time measurements during the fault period are not available due to the lack of Micro-PMUs or communication failures or long time-intervals between data reporting, the model of IIDGs can be utilized to generate pseudo measurements of IIDGs contributions to the fault. IIDGs may follow different control strategies such as suppression of negative sequence current, suppression of active power fluctuations, or suppression of reactive power 
fluctuations. Variety of methods have been proposed to model the fundamental frequency fault response of IIDGs for power systems short circuit analysis. In this paper the method presented in [3], which is based on a grid code requirement, is used for generating the pseudo measurements. It should be emphasized that as the proposed optimal fault location identification method is not restricted to this specific model, it can be replaced by any other models as needed. In the followings the model of [3] is briefly presented:

$$
\begin{aligned}
& \mathrm{I}_{\mathrm{q}-\text { check }}=2\left(1-\mathrm{V}_{\text {IIDG }}^{+}\right) \mathrm{I}_{\mathrm{N}} \\
& \text { If } \mathrm{V}_{\text {IIDG }}^{+}>0.9 \text { then } \mathrm{P}_{\text {IIDG }}=\mathrm{P}_{\text {refo }} \text { and } \mathrm{Q}_{\text {IIDG }}=Q_{\text {refo }} \\
& \text { If } \mathrm{V}_{\mathrm{Pcc}}^{+} \leq 0.9 \\
& \text { If } \mathrm{I}_{\mathrm{q}-\text { check }} \leq \mathrm{I}_{\text {max }} \text { then, } \\
& \quad \mathrm{I}_{\mathrm{q}}=\mathrm{I}_{\mathrm{q}-\text { check }} \text { and } \mathrm{I}_{\mathrm{d}}^{\prime}=\sqrt{\mathrm{I}_{\text {max }}{ }^{2}-\mathrm{I}_{\mathrm{q}-\text { check }}} \\
& \quad \text { If } \mathrm{I}_{\mathrm{q}-\text { check }}>\mathrm{I}_{\text {max }} \text { then, } \mathrm{I}_{\mathrm{q}}=\mathrm{I}_{\text {max }} \text { and } \mathrm{I}_{\mathrm{d}}^{\prime}=0 \text { and } \\
& \mathrm{P}_{\text {IIDG }}=\frac{3}{2} \mathrm{~V}_{\text {IIDG }}^{+} \mathrm{I}_{\mathrm{d}}^{\prime} \text { and } \mathrm{Q}_{\text {IIDG }}=\frac{3}{2} \mathrm{~V}_{\text {IIDG }}^{+} \mathrm{I}_{\mathrm{q}}
\end{aligned}
$$

$P_{\text {refo }}$ and $Q_{\text {refo }}$ are pre-fault dispatched active and reactive powers of IIDGs, and $\mathrm{V}_{\mathrm{Pcc}}^{+}$is the positive sequence value of the point of common coupling, and $\mathrm{I}_{\mathrm{N}}$ is the nominal current.

To integrate (18) into the proposed method, the following procedure is proposed. The model in (18) includes a conditional statement on $\mathrm{V}_{\text {IIDG }}^{+}$. Different approaches can be used to model such conditional statements [4]. The followings express the conditional statement on $\mathrm{V}_{\text {IIDG }}^{+}$without any integers:

$\mathrm{V}_{\text {IIDG }}^{+}-0.9=\mathrm{S}_{1}^{\mathrm{V}}-\mathrm{S}_{2}^{\mathrm{V}}, \quad \mathrm{S}_{1}^{\mathrm{V}}\left(1-\mathrm{S}^{\mathrm{V}}\right)+\mathrm{S}_{2}^{\mathrm{V}} \mathrm{S}^{\mathrm{V}}=0$

$\mathrm{S}_{1}^{\mathrm{V}} \mathrm{S}_{2}^{\mathrm{V}} \leq 0, \quad \mathrm{~S}_{1}^{\mathrm{V}} \geq 0, \quad \mathrm{~S}_{2}^{\mathrm{V}} \geq 0, \quad 0 \leq \mathrm{S}^{\mathrm{V}}$

Where $S_{1}^{\mathrm{V}}$ and $S_{2}^{\mathrm{V}}$ are slack variables and $S^{\mathrm{V}}$ is a variable that becomes 1 if $\mathrm{V}_{\text {IIDG }}^{+}>0.9$ and becomes zero if $\mathrm{V}_{\text {IIDG }}^{+} \leq 0.9 . \mathrm{S}^{\mathrm{V}}$ is also added to (17), objective function of the optimization, so that for the case of $\mathrm{V}_{\text {IIDG }}^{+}=0.9$, the value of $S^{V}$ becomes zero.

Similar to (19), equations should be written for the conditional statement on $\mathrm{I}_{\mathrm{q}-\text { check }}$ as follows:

$\mathrm{I}_{\mathrm{q}-\text { check }}-\mathrm{I}_{\max }=\mathrm{S}_{1}^{\mathrm{I}}-\mathrm{S}_{2}^{\mathrm{I}}, \quad \mathrm{S}_{1}^{\mathrm{I}}\left(1-\mathrm{S}^{\mathrm{I}}\right)+\mathrm{S}_{2}^{\mathrm{I}} \mathrm{S}^{\mathrm{I}}=0$

$S_{1}^{I} S_{2}^{I} \leq 0, \quad S_{1}^{I} \geq 0, \quad S_{1}^{I} \geq 0, \quad 0 \leq S^{\mathrm{I}}$

Where $S^{I}$ is a positive real valued variable that becomes 1 if $\mathrm{I}_{\mathrm{q}-\text { check }}>\mathrm{I}_{\max }$ and becomes zero if $\mathrm{I}_{\mathrm{q}-\text { check }} \leq \mathrm{I}_{\max }$.

The value of $I_{d}$ and $I_{d}$ can be presented as follows:

$\mathrm{I}_{\mathrm{q}}=\left(1-\mathrm{S}^{\mathrm{I}}\right) \mathrm{I}_{\mathrm{q}-\text { check }}+\mathrm{S}^{\mathrm{I}} \mathrm{I}_{\max }$

$I_{d}=\left(1-S^{I}\right) I_{d}^{\prime}$

The injected powers by IIDGs can be presented as follows:

$\mathrm{P}_{\text {IIDG }}=\left(1-\mathrm{S}^{\mathrm{V}}\right) \frac{3}{2} \mathrm{~V}_{\mathrm{IIDG}}^{+} \mathrm{I}_{\mathrm{d}}+\mathrm{S}^{\mathrm{V}} \mathrm{P}_{\text {refo }}$

$\mathrm{Q}_{\text {IIDG }}=\left(1-\mathrm{S}^{\mathrm{V}}\right) \frac{3}{2} \mathrm{~V}_{\text {IIDG }}^{+} \mathrm{I}_{\mathrm{q}}+\mathrm{S}^{\mathrm{V}} \mathrm{Q}_{\text {refo }}$

As distribution systems are operated radially, and pseudo measurements of loads are available and voltage and current measurements are available at least at the substation/ root node, the proposed optimal fault location identification method can uniquely determine the values of the unknown variables.

To identify the fault location, the following two-stage approach is proposed. In the first stage, which is called screening stage, each node of the distribution system is considered as a potential location of the fault. It means that the fictitious node, which represents the fault, is placed at real nodes of the system (i.e. $x=0$ in Fig. 2). If the line between a
TABLE I. Fault location results for fault at $\mathrm{x}=0.2$ of the line

\begin{tabular}{c|c|c|c|c|c|c|c|c|c}
\hline Rf & \multicolumn{3}{|c|}{$0 \Omega$} & \multicolumn{3}{c|}{$10 \Omega$} & \multicolumn{3}{c}{$20 \Omega$} \\
\hline $\begin{array}{c}\text { Load } \\
\text { Error }\end{array}$ & $0 \%$ & $20 \%$ & $50 \%$ & $0 \%$ & $20 \%$ & $50 \%$ & $0 \%$ & $20 \%$ & $50 \%$ \\
\hline a-g & 0.19973 & 0.19965 & 0.19953 & 0.20077 & 0.20099 & 0.20133 & 0.20104 & 0.20137 & 0.20186 \\
\hline a-b & 0.20032 & 0.20041 & 0.20056 & 0.20023 & 0.20030 & 0.20042 & 0.20055 & 0.20072 & 0.20098 \\
\hline a-b-g & 0.20002 & 0.20003 & 0.20003 & 0.20010 & 0.20013 & 0.20016 & 0.20006 & 0.20008 & 0.20012 \\
\hline 3Ф-g & 0.20003 & 0.20004 & 0.20006 & 0.20049 & 0.20054 & 0.20061 & 0.20088 & 0.20089 & 0.20091 \\
\hline
\end{tabular}

given pair of nodes is long, the fictitious node can be placed at $\mathrm{x}=0.5$ as well. This reduces the nonlinearity of the equations which makes the screening process faster. Nodes with smallest values of the objective function in (17) are selected as the short list for potential location of the fault. In the second stage, the proposed method with $\mathrm{x}$ as an unknown variable is executed. The fault location result with minimum value of the objective function in (17) is identified as the actual location of the fault.

Note that in (8)-(11), considering the $\pi$ model increases the nonlinearity of the model of the faulted line. In a faulted short line, the shunt elements can be ignored. If needed, long lines can also be divided into smaller lines for modeling faulted lines.

Note that if discrete/status data such as signals from fault indicators, smart meters notifications and trip signals of protective devices are also available, the method in [2] can be used to reduce the search space of the first stage of the proposed method which further expedites the process.

\section{SIMULATION RESULTS}

The proposed fault location method is applied to the modified IEEE 34-node test feeder where two $100 \mathrm{kVA}$ distributed generators are connected to the system at nodes 828 and 834. In addition to voltage and current measurements at the substation, two Micro-PMUs are placed at nodes 824 and 832, and one legacy measuring device is placed at node 860 . Pseudo measurement of loads are also available with uncertainties inaccuracies listed in Table. I. The performance of the proposed method is tested in variety of conditions. Table I represents some of the results for a fault at line between nodes 852-854. According to the simulation results, the location of the fault can be identified precisely.

\section{CONCLUSION}

This paper proposed an optimal fault location identification method for distribution systems with IIDGs. It can fully utilize all types of data with different accuracies for enhancing the results in the presence of uncertainties and different load types. Simulation results demonstrated the proposed method can precisely identify the location of faults.

\section{REFERENCES}

[1] S. Lotfifard, "Automated Fault Location in Smart Distribution Systems" Ph.D. dissertation, Dept. Elect. And Com. Eng., Texas A\&M, USA, 2011.

[2] I. Kiaei, S. Lotfifard, "Fault Section Identification in Smart Distribution Systems Using Multi-source Data" IEEE Trans. Smart Grid, vol. 11, no.1, pp. 74- 83, 2020.

[3] L. Strezoski, M. Prica, and K. A. Loparo, "Sequence Domain Calculation of Active Unbalanced Distribution Systems Affected by Complex Short Circuits" IEEE Trans. Power Syst., vol. 33, no. 2, pp. 1891-1902, 2018.

[4] K. M. Powell, A. N. Eaton, J. D. Hedengren, and T. F. Edgar "A Continuous Formulation for Logical Decisions in Differential Algebraic Systems using Mathematical Programs with Complementarity Constraints" Processes, vol.4, no.1, pp. 1-23, 2016. 